\title{
Adaptive and Innate Immune Responses in Autism: Rationale for Therapeutic Use of Intravenous Immunoglobulin
}

\author{
Sudhir Gupta - Daljeet Samra • Sudhanshu Agrawal
}

Published online: 15 April 2010

(C) The Author(s) 2010. This article is published with open access at Springerlink.com

\begin{abstract}
Background Autism is a complex polygenic neurodevelopmental disorder characterized by deficits in communication and social interactions as well as specific stereotypical behaviors. Both genetic and environmental factors appear to contribute to the pathogenesis of autism. Accumulating data including changes in immune responses, linkage to major histocompatibility complex antigens, and the presence of autoantibodies to neural tissues/antigens suggest that the immune system plays an important role in its pathogenesis.

Summary In this brief review, we discuss the data regarding changes in both innate and adaptive immunity in autism and the evidence in favor of the role of the immune system, especially of maternal autoantibodies in the pathogenesis of a subset of patients with autism. The rationale for possible therapeutic use of intravenous immunoglobulin is also discussed.
\end{abstract}

Keywords Cytokines · chemokines · autoantibodies . dendritic cells $\cdot$ CVID $\cdot$ lymphocyte subsets $\cdot$ IVIG $\cdot$ IgG . IgG subclasses

\section{Introduction}

A complex polygenic neurodevelopmental disorder, autism is characterized by deficits in communication and social interactions as well as specific stereotypical behaviors. It is perhaps the most common pediatric disorder, occurring in 1 in 160 children. Both genetic and environmental factors

S. Gupta $(\bowtie) \cdot$ D. Samra $\cdot$ S. Agrawal

Division of Basic and Clinical Immunology, Medical Sciences I,

C-240, University of California at Irvine,

Irvine, CA 92697, USA

e-mail:sgupta@uci.edu appear to play an important role. Because the response to environmental factors is under the regulation of immune response genes, it is not surprising that a number of immunological abnormalities and an increased association with certain major histocompatibility complex (MHC) genes have been observed in autism. The disorder is three to four times more common in boys than girls; however, the basis of preponderance in males is unclear. Immunological abnormalities in both the innate and adaptive immune system that are manifested by a paradox of immunodeficiency, inflammation, and autoimmunity have been reported in autism. Immunological abnormalities include depressed cell-mediated immunity and antibody-mediated immunity, increased production of proinflammatory cytokines and chemokines, and the presence of autoantibodies against various neural tissues and antigens (reviewed in Refs. [1-4]).

Furthermore, the presence of autoantibodies against neuronal antigens in mothers of autistic children and in children with autism and the induction of stereotypical changes in mice and rhesus monkeys by autistic maternal immunoglobulin $\mathrm{G}$ (IgG) [5-8] argues in favor of the role of the immune system in the pathogenesis of a subset of patients with autism. Therefore, it is not surprising that some studies have reported the beneficial effect of intravenous immunoglobulin (IVIG). Here we have reviewed immunological abnormalities in autism spectrum disorders (ASD) and their response to biological therapies, with a special emphasis on IVIG. Because of the space limitation for references, only selected ones have been cited.

Adaptive Immune Response

Alterations in both T cell- and B cell-mediated immunity in ASD have been reported. However, these changes are observed in a subset of patients with ASD. 


\section{T Cell-Mediated Immunity}

Depressed in vitro response to mitogens (phytohemagglutinin [PHA], concanavalin A, pokeweed mitogen) and recall antigens (mumps, tetanus toxoid, Candida albicans), and decreased proportions of $\mathrm{CD}^{+}, \mathrm{CD}^{+}$and $\mathrm{CD}^{+}{ }^{+} \mathrm{T}$ cells have been reported [1-4]. We also have observed a decrease in $\mathrm{CD} 8^{+} \mathrm{CCR} 7^{+} \mathrm{CD} 45 \mathrm{RA}^{-} \mathrm{CD} 8^{+}$central memory $\mathrm{T}$ cells. Furthermore, there is a shift from Th1 to Th2 cytokine type of $\mathrm{CD}^{+}$and $\mathrm{CD} 8^{+}$cells [9]. Patients with autism have been shown to have decreased intracellular interferon- $\gamma$ (IFN- $\gamma$ ) and interleukin (IL)-2 containing $\mathrm{CD}^{+}$and $\mathrm{CD}^{+} \mathrm{T}$ cells, whereas IL-4 containing cells are increased. In contrast, Singh and colleagues reported increased plasma levels of IFN- $\gamma$ (reviewed in Ref. [3]). However, in CD3 plus CD28-stimulated peripheral blood mononuclear cell (PBMC) culture supernatants, we did not observe any increased levels of IFN- $\gamma$ (Fig. 1a). We also reported that PHA-induced TNF- $\alpha$ production is increased in autism [10].

\section{B Cell-Mediated Immunity}

Immunoglobulin abnormalities were among the most common immune abnormalities observed in children with autism. In 150 patients (compared with the ranges for agematched controls), we observed 10 children with common variable immunodeficiency (CVID), 20 patients with low total $\operatorname{IgG}$ (hypogammaglobulinemia), 4 with $\operatorname{IgG}$ subclass deficiency, and 3 with selective $\operatorname{IgA}$ deficiency $(<7 \mathrm{mg} / \mathrm{dl})$. Many of these children had a history of increased episodes of recurrent upper respiratory tract infections including otitis media. Furthermore, $10 \%$ of children (4 years and older) did not respond to one or more antigens to immunized antigens. Forty patients had elevated IgE. However, clinical manifestations of type I hypersensitivity does not appear to be increased in autism. Also, the proportions and numbers of circulating B cells appear to be normal. Other investigators also have reported abnormalities in Ig levels [2, 3]; however, the frequency of abnormalities is much lower than ours. Our data may be skewed because patients referred to us have suspected immunological abnormalities. Many of these children are on a gluten- and casein-free diet; however, there is no evidence of an increased incidence of celiac disease (antibodies to casein, gluten, or tissue transglutamic acid) in autism.

\section{Autoimmunity in Autism}

A theory of autoimmunity in autism has been proposed for more than 25 years. There appears to be an increased prevalence of autoimmune disease in family members of children with autism. Furthermore, there is an increased incidence of certain MHC genes in children with autism compared with controls. In 1982, Weizman and colleagues [11] first reported an abnormal immune response to brain tissues in children with autism. Since then, a number of autoantibodies against various neural antigens have been reported in a large subset of children with autism. These include myelin basic protein, glial fibrillary acid protein, and neuron axon filament protein. In addition, antibodies against nerve growth factor, antibrain endothelial cell proteins, serotonin receptors, and anti- $\alpha_{2}$-adrenergic binding sites have been reported in autism (reviewed in Ref. [3]). One of the most intriguing observations is that we did not find an increased frequency of non-organ-specific autoantibodies (e.g., antinuclear antibodies (ANA), rheumatoid factor (RF)) in children with autism (S. Gupta, unpublished personal observation).

In addition to the presence of autoantibodies in children with autism, Warren and colleagues [12] were the first to suggest a role of maternal antibodies in the pathogenesis of the disorder. They demonstrated the presence of autoantibodies in maternal serum that reacted with the lymphocytes of affected children. However, Dalton and associates [5] were the first to demonstrate the presence of antibodies in
Fig. 1 Production of IL-17 (a) and IFN- $\gamma(\mathbf{b})$ from anti-CD3 plus anti-CD28 monoclonal antibody-stimulated mononuclear cells from autism [17] and controls [15]
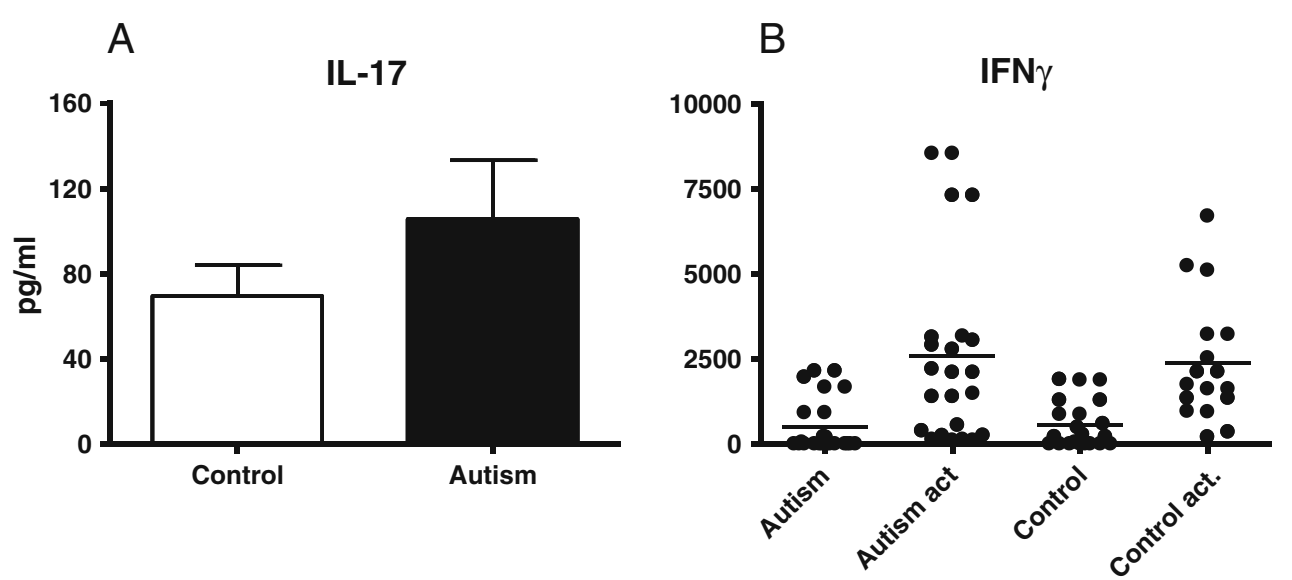
maternal serum of an autistic child that reacted with Purkinje neurons and other large ones in the adult rat cerebellum and brainstem, neonatal cerebellum, and surface antigens of neuroblastoma cell line NB-1. When autism maternal serum was injected into pregnant mice, the offspring reported behavioral changes and a modest reduction in the concentrations of choline and creatine relative to water; no changes were seen in the controls.

Singer and colleagues [6] performed an exhaustive analysis of autism maternal antibodies for their reactivity to fetal, adult human, and rodent brain tissues. Using homogenates of whole brain tissue or tissue from a specific area of the brain, they reported reactivity with 36-, 39-, and $61-\mathrm{kDa}$ antigens of human fetal brain. A significant correlation was observed between mothers having offspring with autistic disorder and the presence of serum antibodies against $39-$ and $36-\mathrm{kDa}$ antigens, but not with antibodies against $61-\mathrm{kDa}$ antigens. However, these antibodies did not predict the outcome of future offspring. Therefore, it is likely that a complex interaction between maternal antibodies and genetic factors, rather than the direct effect of maternal antibodies, plays a role in the pathogenesis of autism. No antibodies to myelin basic protein (MBP), glial fibrillary acid protein (GFAP), or nerve growth factor were observed in the maternal serum of children with autism.

Braunschweig and colleagues [7] reported reactivity of maternal serum of children with autism (11.5\%) with both 37- and 73-kDa antigens of fetal human brain but not adult human brain. In addition, the presence of these two antibodies was associated with behavioral regression. These investigators then examined whether autism maternal antibodies would induce behavioral changes in rhesus monkeys [8]. They purified IgG from mothers of children with autism who were positive for antibodies against fetal human brain antigens and from mothers of normally developing children and then administered the $\operatorname{IgG}$ to four pregnant rhesus monkeys. Five untreated pregnant monkeys were also included in the control group. Monkeys born to mothers administered with autism maternal serum demonstrated increased whole body stereotypies across multiple testing paradigms. These monkeys were also hyperactive. In contrast, monkeys born to mothers treated with IgG from mothers of normally developing children and untreated monkeys did not show any significant changes in stereotypies.

\section{Association with MHC}

Additional evidence of the role of the immune system in autism comes from an association of autism with certain MHC genes. An association was shown with the $\mathrm{C} 4 \mathrm{~b}$ null allele of the $\mathrm{C} 4 \mathrm{~b}$ gene, the extended haplotype B44-S30DR4 (44 allele of the HLA-B, the S allele of the BF gene, the 3 allele of CD4A, the C4b null allele, and the DR4 allele), which is in linkage disequilibrium with MHC class III and with the third hypervariable region of DR $\beta 1$ allele [13]. The strongest association has been observed between the null allele of $\mathrm{C} 4 \mathrm{~b}$ in MHC class III region and autism. These authors suggested that the low levels of $\mathrm{C} 4$ may be important in the pathogenesis of autism because $\mathrm{C} 4$ has been observed in developing brain neurons. It is interesting that the allele for TNF- $\alpha$ gene is also located in MHC class III just telomeric to $\mathrm{C} 4$, and TNF- $\alpha$ production is increased in autism. HLA-DR4 also has been observed with an increased frequency in mothers of children with ASD and in their sons with autism [14].

\section{Innate Immune Response}

Natural killer (NK) cells, antigen-presenting cells (APC), and complement proteins are critical components of innate immunity. More than 20 years ago, Warren and associates described decreased NK cell cytotoxicity in children with autism. More recently, Enstrom et al. [15] analyzed gene expression and functions of NK cells in children with ASD. An increased expression of genes for killer cell immunoglobulin receptors and for perforin and granzyme was observed in ASD. An increased expression of both perforin and granzyme in NK cells in ASD was confirmed by flow cytometry. They also observed that baseline as well as stimulated NK cell cytotoxicity activity was significantly reduced in ASD. Total hemolytic complement (CH50) and $\mathrm{C} 3$ are normal; however, levels of total $\mathrm{C} 4$, particularly $\mathrm{C} 4 \mathrm{~b}$, are significantly lower in autism compared with controls.

\section{Dendritic Cells}

Macrophages and dendritic cells (DCs) are two major APCs; DCs prime naive T cells to differentiate into Th1, Th2, Th17, and Treg cells, whereas macrophages promote effector functions of primed T cells [16]. The differentiation of naive $\mathrm{CD}^{+} \mathrm{T}$ cells to different subsets by $\mathrm{DC}$ is mediated by distinct cytokines and distinct transcription factors. Using lineage-specific markers and markers specific for myeloid DCs (mDCs) and plasmacytoid DCs (pDCs), we analyzed subpopulations of DCs in the peripheral blood of children with autism. No significant difference was observed in the proportions of $\mathrm{mDCs}$ and $\mathrm{pDCs}$ between autism and controls (Fig. 2). Because IL-17 (Th17) plays an important role in autoimmunity and inflammation and there is evidence of increased autoimmunity in autism, we examined the production of IL-17 by T cells. No significant difference was observed in IL-17 production by PBMCs stimulated with anti-CD3 plus anti-CD28 monoclonal antibody (Fig. 1b). Similar results were reported by Onore and colleagues [17] in PHA-stimulated PBMCs. Because IL-23 promotes the production of IL-17, the researchers 
Fig. 2 Circulating total dendritic cells $(D C)$, and plasmacytoid $(p D C)$ and monocytoid dendritic cells $(m D C)$ in autism and controls. No significant difference was observed between autism and controls
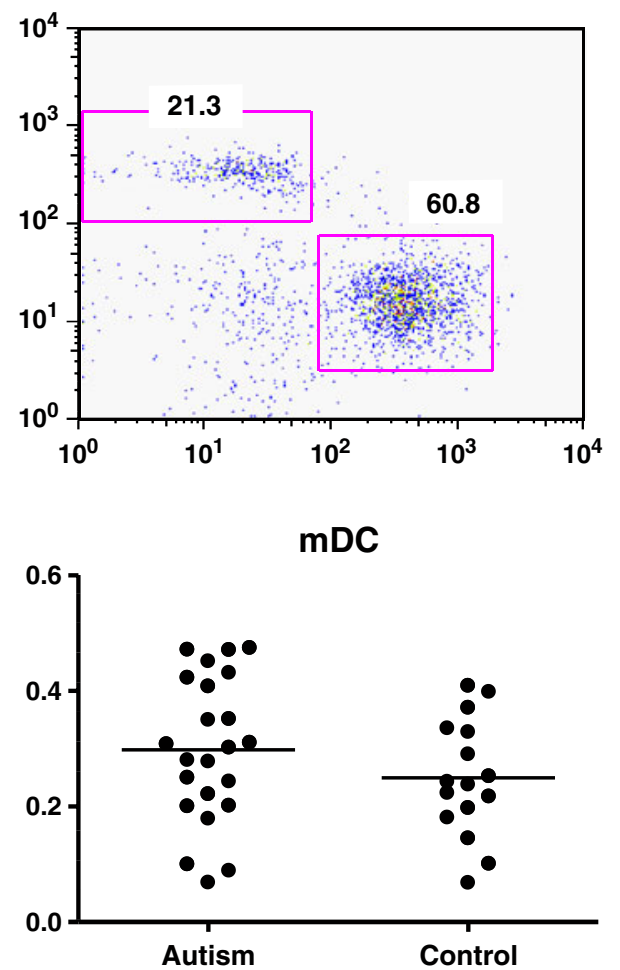
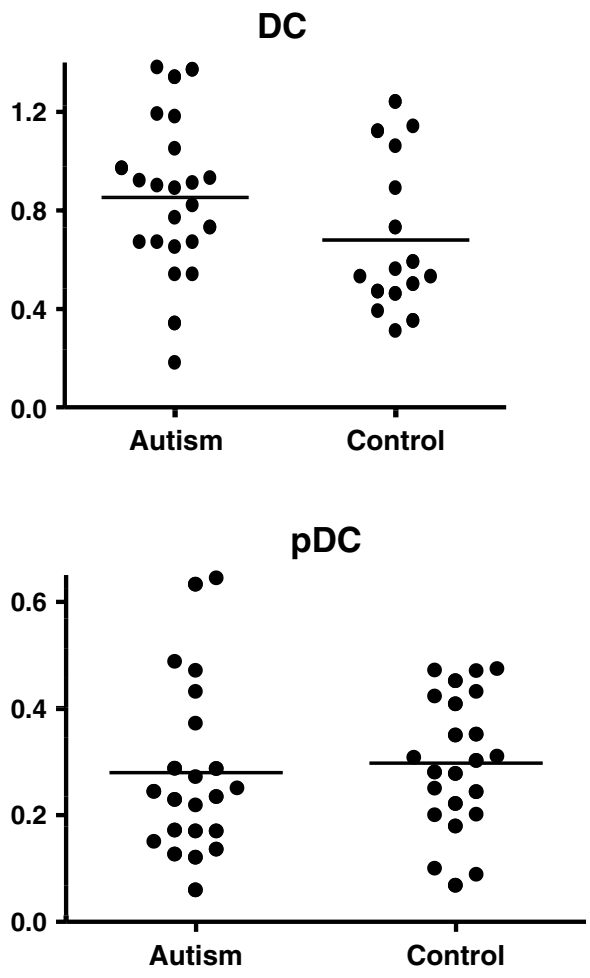

examined the production of IL-23 by PBMC stimulated with PHA. They reported a significantly decreased production of IL-23 in the ASD group. However, when data are analyzed for individual patients, the levels of IL-23 are within the range for healthy controls. In contrast, Jyonouchi et al. [18] reported an increase in lipopolysaccharide (LPS)induced IL-23 production in children with ASD. The reasons for this discrepancy remain unclear. There are no published data on Treg cells in ASD.

\section{Monocyte/Macrophages}

Increased monocyte counts have been reported in children with autism compared with controls. In addition, increased levels of proinflammatory cytokines and chemokines, including IL-1 $\beta$, IL-6, TNF- $\alpha$, macrophage chemoattractant (MCP)-1, and macrophage inflammatory protein (MIP)-1 $\beta$ in the cerebrospinal fluid (CSF), and activation of microglia and astroglia in patients with ASD have been reported [19-21]. We first reported an increased production of LPS-activated peripheral blood macrophage-derived TNF- $\alpha$ in patients with autism [10]. Enstrom et al. [22] and Jyonouchi et al. [18] reported an increased production of IL-1 $\beta$, IL-6, TNF- $\alpha$, and GM-CSF production by monocytes stimulated with Toll-like receptor ligands in ASD. Many of these cytokines may be considered neuropoietic cytokines. For example, IL-6 can directly affect neurons and glial cells and regulate their growth, survival and death, and neurite outgrowth. TNF- $\alpha$ can induce behavioral changes and reduce cerebral blood flow. We also observed significantly increased plasma levels of IL-6, TNF- $\alpha$, and MCP-1 in children with autism compared with controls (Fig. 3). These data suggest that innate immune response may play a role in the pathogenesis of ASDs.

\section{Biological Therapy in Autism}

Several biological treatments have been used in treating autism. Some of these studies have been published and others have been presented at various conferences (reviewed in Ref. [4]). These include transfer factor, fibroblast growth factor, and IVIG. IVIG has been used in children with autism based on the rationale of the presence of antibody deficiency and autoimmunity in autism; however, data on the beneficial effects are conflicting. Gupta et al. [1] in an open-label study of 10 children with autism (nine aged 2 to 6 years and one aged 12 years) and IgG, IgG subclass deficiency, specific antibody deficiency, or common variable immunodeficiency were treated with IVIG at $400 \mathrm{mg} / \mathrm{kg} / 4$ weeks for 6 months to 18 months. A significant improvement in behavioral characteristics, eye contact, social interactions, and echolalia were observed. Expressive speech improved in two patients. The 12-yearold patient displayed minimal improvement after 1 year of therapy. These data suggest that IVIG may be beneficial in younger children with autism. Furthermore, we have 
Fig. 3 Plasma levels of IL-6, TNF- $\alpha$, and MCP-1 in autism and controls. A significant increase $(P \leq 0.05)$ was observed in autism compared with controls
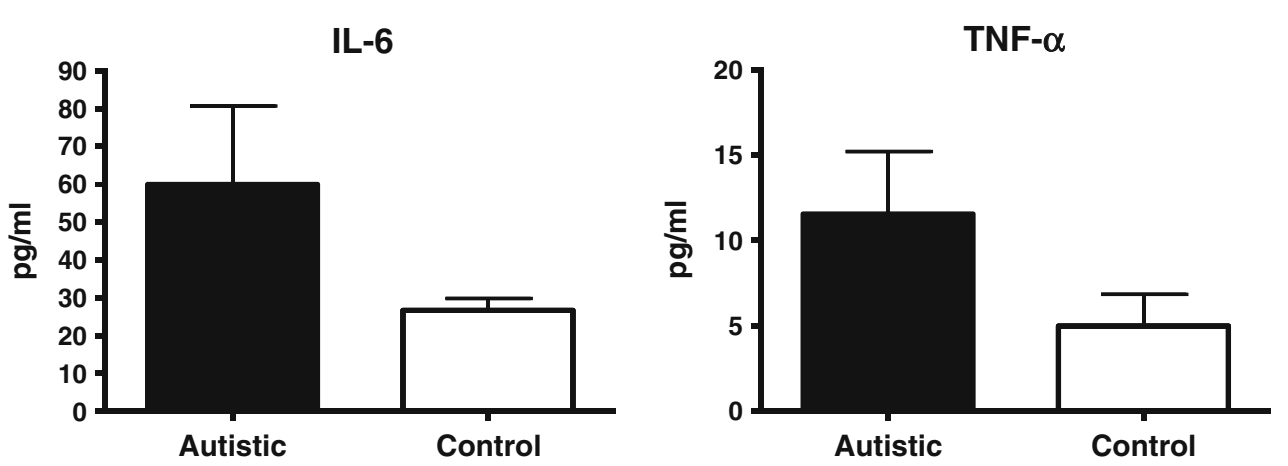

MCP-1

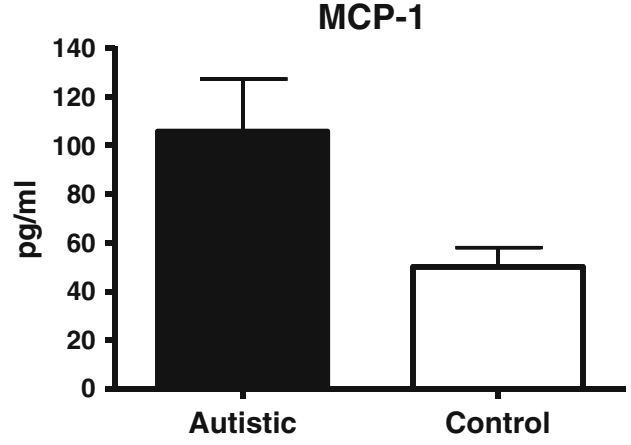

observed that the higher dose of $800 \mathrm{mg} / \mathrm{kg} / 4$ weeks has a better response (S. Gupta, unpublished observation). Oleske [23] treated 27 children (aged 2 to 10 years) with autism who also had low IgG (5), low IgG subclass (12), and specific antibody deficiency with recurrent infections (10), with IVIG (400 mg-1 $\mathrm{g} / \mathrm{kg} / 3$ weeks for 6-18 months). Twenty-one of the 27 children showed improvement in autistic behavior. Boris et al. [24] treated 26 patients with autism (aged 3-17 years; average 6.7 years) with IVIG at $400 \mathrm{mg} / \mathrm{kg} / 4$ weeks for six infusions. No immunological profile was documented. A significant improvement (ANOVA) was observed in total aberrant behavior score as well as in hyperactivity, inappropriate speech, irritability, lethargy, and stereotypy. Possible mechanisms for the beneficial effects seen may be due to the replacement effect of IVIG on recurrent upper respiratory tract infections (during infections autistic behaviors worsen), and the immunomodulatory effects of IVIG on autoantibodies and inflammatory cytokines (e.g., inhibits TNF- $\alpha$ production).

Plioplys [25] treated 10 children with autism (4-17 years; three children of 4-6 years) with normal serum immunoglobulins. The actual IVIG dose administered ranged from 154 to $375 \mathrm{mg} / \mathrm{kg}$ at 6-week interval. The number of infusions ranged from 1 to 6 . Six of ten children received four infusions, and one child each had one, three, five, and six infusions. One patient showed significant improvement, with almost complete amelioration of autistic symptoms. DelGiudice-Asch et al. [26] treated five children with autism with IVIG at $400 \mathrm{mg} / \mathrm{kg} / \mathrm{month}$ for 6 months. Using
10 assessment scales, only the Ritvo-Freeman Real Life Rating Scale, the sensory response, showed a clinically meaningful response. Therefore, three studies of 63 subjects (two studies of 37 patients included subjects who had underlying Ig-specific antibody deficiency) demonstrated significant improvement, whereas one study of 10 subjects with unconventional dosing and intervals and a short 6-week duration, and another study of 5 patients in a 6-month treatment did not show significant improvement.

The Primary Immunodeficiency Committee of the American Academy of Allergy, Asthma, and Immunology listed autism among the disorders that are unlikely to benefit from IVIG treatment [27]. The committee cited the two above-mentioned negative studies [25, 26] - the first with 10 cases with unconventional dosing, interval, and a small number of IVIG infusions [25], and the second [26] with five cases - without citing the original study of 15 patients with positive results [1]. Therefore, such a conclusion by the committee appears to be unjustified because more studies of large numbers of patients treated with an appropriate dosage of IVIG and for longer durations demonstrated beneficial effects [1, 23, 24]. Based on the above data, such a conclusion is unjustified.

Interestingly, Perlmutter et al. [28], in a double-blind controlled study, reported the beneficial effect of high-dose IVIG in obsessive-compulsive disorder and tic disorders, including pediatric autoimmune neuropsychiatric disorders associated with streptococcal infections. Zykov et al. [29] in an open-label study reported the beneficial effect of IVIG 
treatment in patients with Tourette's syndrome who had serum antibodies to caudate nucleus.

Because patients with autism display IgG or IgG subclass deficiency, the presence of autoantibodies, and an increased production of proinflammatory cytokines and chemokines, and IVIG is used as a replacement therapy and plays an important immunomodulatory role in autoantibody production and proinflammatory chemokine and cytokine secretion, a good rationale exists for the use of IVIG in at least a subset of patients with autism. Therefore, there is a need for a well-designed controlled study to determine the efficacy of IVIG in ASDs.

\section{Summary}

ASD are associated with dysregulated immune responses represented with a paradox of deficient $\mathrm{T}$ cell- and $\mathrm{B}$ cellmediated responses, increased inflammatory mediator production in both the periphery and the brain, and the presence of autoantibodies against various neural tissues and antigens in the serum of children with ASD and in the serum of their mothers. These abnormalities are observed in a subset of patients and their mothers. A role of the immune system (especially autoantibodies) in a subset of patients is supported by the induction of stereotypies and hyperactivity in mice and rhesus monkeys by the administration of serum/IgG from mothers of children with autism who are positive for antibodies against neural antigens. A role of autoimmunity is further supported by the increased frequency of certain alleles in class II and class III regions of MHC in children with autism as well as in the mothers of children with autism. Because of Ig/antibody deficiency and autoimmunity in autism, there is a rationale for the therapeutic use of IVIG in autism; however, the results of open-label and uncontrolled studies are conflicting, which may be due to differences in patient age, the presence or absence of $\mathrm{Ig}$ /antibody deficiency and/or autoantibodies, and dosing and duration of IVIG treatment. Thus, there is a need for a well-controlled double-blind clinical trial with replacement and immunomodulatory doses of IVIG in ASDs.

Open Access This article is distributed under the terms of the Creative Commons Attribution Noncommercial License which permits any noncommercial use, distribution, and reproduction in any medium, provided the original author(s) and source are credited.

\section{References}

1. Gupta S, Head C, Aggarwal S. Dysregulated immune system in children with autism. Beneficial effects of intravenous immuno- globulin on autistic characteristics. J Autism Dev Disord. 1996;26:439-52.

2. Cohly HH, Panja A. Immunological findings in autism. Int Rev Neurobiol. 2005;71:317-41.

3. Ashwood P, Wills S, Van de Water J. The immune response in autism: a new frontier for autism research. J Leukoc Biol. 2006;80:1-5.

4. Gupta S. Immunological treatment for autism. J Autism Dev Disord. 2000;30:475-9.

5. Dalton P, Deacon R, Blamire A, Pike M, McKinley I, Stein J, et al. Maternal neuronal antibodies associated with autism and a language disorder. Ann Neurol. 2003;53:533-7.

6. Singer HS, Morris CM, Gause CD, Gillin PK, Crawford S, Zimmerman AW. Antibodies against fetal brain in sera of mothers with autistic children. Antibodies against fetal brain in sera of mothers with autism children. J Neuroimmunol. 2008;194:165-72.

7. Braunschweig D, Ashwood P, Krakowiak P, Hertz-Picciotto I, Hansen R, Croen LA, et al. Autism: maternally derived antibodies specific for fetal brain proteins. Neurotoxicology. 2008;29:226-31.

8. Martin LA, Ashwood P, Braunschweig D, Cabanlit M, Van de Water J, Amaral DG. Stereotypies and hyperactivity in rhesus monkeys exposed to $\mathrm{IgG}$ from mothers of children with autism. Brain Behav Immun. 2008;22:806-16.

9. Gupta S, Aggarwal S, Rashanravan R, Lee T. Th1- and Th2-like cytokines in CD4+ and CD8+ T cells in autism. J Neuroimmunol. 1998;86:106-9.

10. Gupta S, Rimland B, Schilling PD. Pentoxyphyllin: rationale for possible use in autism. J Child Neurol. 1996;11:501-4.

11. Weizman A, Weizman R, Szekely GA, Wijsenbeek H, Livni E. Abnormal immune response to brain tissue antigen in the syndrome of autism. Am J Psychiatry. 1982;139:1462-5.

12. Warren RP, Cole P, Odell JD, Pingree CB, Warren WL, White E, et al. Detection of maternal antibodies in infantile autism. J Am Acad Child Adolesc Psychiatry. 1990;29:873-7.

13. Torres AR, Maciulis A, Odell D. The association of MHC genes with autism. Front Biosci. 2001;6:D936-43.

14. Lee LC, Zachary AA, Leffell MS, Newschaffer CJ, Matteson KJ, Tylor JD, et al. HLA-DR4 in families with autism. Pediatr Neurol. 2006;35:303-7.

15. Enstrom AM, Lit L, Onore CE, Gregg JP, Hansen RL, Pessah IN, et al. Altered gene expression and function of peripheral blood natural killer cells in children with autism. Brain Behav Immun. 2009;23:124-33.

16. Agrawal A, Agrawal S, Tay J, Gupta S. Biology of dendritic cells in aging. J Clin Immunol. 2008;28:14-20.

17. Onore C, Enstrom A, Krakowiak P, Hertz-Picciotto I, Hansen R, Van de Water J, et al. Decreased cellular IL-23 but not IL-17 production in children with autism spectrum disorders. J Neuroimmunol. 2009;216:126-9.

18. Jyonouchi H, Geng L, Cushing-Ruby A, Quraishi H. Impact of innate immunity in a subset of children with autism spectrum disorders: a case control study. J Neuroinflammation. 2008;5:52.

19. Vargas DL, Nascimbene C, Krishnan C, Zimmerman AW, Pardo CA. Neuroglial activation and neuroinflammation in the brain of patients with autism. Ann Neurol. 2005;57:67-81.

20. Zimmerman AW, Jyonouchi H, Comi AM, Connors SL, Milstien $\mathrm{S}$, Varsou A, et al. Cerebrospinal fluid and serum markers of inflammation in autism. Pediatr Neurol. 2005;33:195-201.

21. Li X, Chauhan A, Sheikh AM, Patil S, Chauhan V, Li XM, et al. Elevated immune response in the brain of autistic patients. J Neuroimmunol. 2009;207:111-6.

22. Enstrom AM, Onore CE, Van de Water JA, Ashwood P. Differential monocyte responses to TLR ligands in children with autism spectrum disorders [published online ahead of print August 8, 2009]. Brain Behav Immun. 2010;24:64-71.

23. Oleske J. Another view of autism. UNMDNJ. Research: 22-23, Winter 2004. 
24. Boris M, Goldblatt A, Edelson SM. Improvement in children with autism treated with intravenous gamma globulin. J Nutr Environ Med. 2006;15:1-8.

25. Plioplys AV. Intravenous immunoglobulin in children with autism. J Child Neurol. 1998;13:79-82.

26. DelGiudice-Asch G, Simon L, Schmeidler J, CunninghamRundles C, Hollander E. Brief report: a pilot clinical trial of intravenous gammaglobulin in childhood autism. J Autism Dev Disord. 2007;29:157-60.

27. Orange JS, Hossny EM, Weiler CR, Ballow M, Berger M, Bonilla FA, et al. Use of intravenous immunoglobulin in human disease: a review of evidence by members of the Primary Immunodeficiency Committee of the American Academy of Allergy, Asthma and Immunology. J Allergy Clin Immunol. 2006;117(4 Suppl):S525-53.

28. Perlmutter SJ, Leitman SF, Garvey MA, Hamburger S, Feldman E, Leonard HL. Therapeutic plasma exchange and intravenous immunoglobulin for obsessive-compulsive disorder and tic disorders in childhood. Lancet. 1999;354:1153-8.

29. Zykov VP, Shcherbina AY, Novikova EB, Shvabrina TV. Neuroimmune aspects of the pathogenesis of Tourette's syndrome and experience in the use of immunoglobulins in children. Neurosci Behav Physiol. 2009;39:635-8. 